University of Vermont

UVM ScholarWorks

College of Agriculture and Life Sciences Faculty

Publications

College of Agriculture and Life Sciences

$7-1-2016$

\title{
Local adaptation or foreign advantage? Effective use of a single- test site common garden to evaluate adaptation across ecological scales
}

Eric J.B. von Wettberg

Florida International University

Edward Marques

Florida International University

Courtney J. Murren

College of Charleston

Follow this and additional works at: https://scholarworks.uvm.edu/calsfac

Part of the Community Health Commons, Human Ecology Commons, Nature and Society Relations Commons, Place and Environment Commons, and the Sustainability Commons

\section{Recommended Citation}

von Wettberg EJ, Marques E, Murren CJ. Local adaptation or foreign advantage? Effective use of a single-test site common garden to evaluate adaptation across ecological scales. New Phytologist. 2016 Jul;211(1):8-10.

This Article is brought to you for free and open access by the College of Agriculture and Life Sciences at UVM ScholarWorks. It has been accepted for inclusion in College of Agriculture and Life Sciences Faculty Publications by an authorized administrator of UVM ScholarWorks. For more information, please contact scholarworks@uvm.edu. 


\section{Local adaptation or foreign advantage? Effective use of a single-test site common garden to evaluate adaptation across ecological scales}

Since the groundbreaking work of Turesson (1922) and Clausen and colleagues (e.g. Heisey et al., 1942; Núñez-Farfán \& Schlichting, 2001), local adaptation of plant populations has been assessed in plant species with a variety of life histories and habitats. Several reviews and quantitative syntheses have determined that local adaptation is pervasive, although not universal, across plant species (e.g. Hoeksema \& Forde, 2008; Hereford, 2009), even in recently introduced invasive taxa (Oduor et al., 2016). Local adaptation may often be a consequence of fitness trade-offs between habitats (Kawecki \& Ebert, 2004), but can also be affected by demographic factors such as drift, gene flow and mutation-rate variation. Although widely acknowledged as important, determining the best definition, and best measures of local adaptation particularly across diverse life histories remain a source of disagreement and a challenge; there is a need for models where fitness components are evaluated across life stages. In this issue of New Phytologist Peterson et al. (pp. 345-356) expertly surmount complications of measuring local adaptation in common-garden experiments using several populations of the geographically widespread monkey flower, Mimulus guttatus with variable life histories and ecologies.

\section{'Common-garden studies such as this can help target the} most informative comparisons of populations and focal traits.

Local adaptation is commonly operationally defined in two ways: 'local vs foreign', where individuals from a focal population or habitat outperform conspecific individuals transplanted from other populations or habitats, or as 'home vs away', (or sympatric vs allopatric) where a focal genotype performs better in its habitat of origin than it does in another habitat (Blanquart et al., 2013). Experiments that use reciprocal-transplant designs can result in a

This article is a commentary on Peterson et al., 211: 345-356. variety of outcomes, with local germplasm performing best in all sites, only in some sites, or in none. Furthermore, sometimes a population may perform better at home than elsewhere, and sometimes not. Specific patterns, of course, depend on the architecture of adaptations, costs and trade-offs to local performance, the relative fertility or toxicity of sites, and the ecological history of the seed source. Reciprocal-transplant experiments have been the gold standard for dissecting these effects since the work of Clausen and colleagues. However, with multiple sites such designs rapidly become sufficiently daunting logistically that compromises are required. In some cases, such as when there are multiple hierarchical scales of adaptation (i.e. to specific sites, habitat types, and climatic regions), experimental designs become so large they are unable to simultaneously detect local adaptation between habitat types as well as between sites within a habitat. For some aspects of local adaptation, single-site common-garden experiments may provide a more manageable experimental approach where it is possible to delve deeper into patterns. The work from Peterson et al. is just such an example.

Mimulus guttatus occurs in a wide geographic and ecological range of habitats from coastal bluffs to serpentine seeps and montane stream banks. It also has two life-history races, annual and short-lived perennial, that are partially reproductively isolated by a chromosomal inversion (Nesom, 2012). This diversity of lifehistory strategies and variation across diverse habitats make comparing life forms in the same experiment across multiple sites complicated. Typically, two habitat types of Mimulus have been compared (e.g. Ivey et al., 2004; Hall \& Willis, 2006; Lowry et al., 2008), but none have used more than a small number of populations. To examine more populations together across a gradient of life histories from the M. guttatus species complex, Peterson et al. used a single montane site with detailed measurements and life-history matrix modeling to expand their scope. They planted several different ecotypes of the $M$. guttatus species complex from 11 different populations into a stream site. Over two growing seasons they tracked survival, different aspects of reproduction, and recruitment, and then integrated across the lifespan by calculating population growth rates (Lambda) which are more appropriate fitness measures than a measure of a single fitness component such as seed set. This approach is particularly useful when lifespan varies so extensively, from annual to perennial, but would be generally useful for dissection of differences in fitness. Employing life-table response experiments (Caswell, 2001) allowed Peterson et al. to evaluate which components of fitness most contribute to increased performance. By comparing performance of the 10 foreign populations to the native population, inference about local adaptation vs foreign advantage was possible. As populations varied in life forms (annual vs perennial) and habitat types (coastal, inland, low elevation, high elevation) hierarchical levels of ecological variation could be examined. 
Peterson etal. find mixed evidence for local adaptation, consistent with the complex hierarchy of variation that many have observed in Mimulus. Annual populations performed poorly in this site, where a perennial form is native. The contribution of rosettes overwintering gave perennial forms an advantage in the common garden montane stream-bank site, showing the poor match of annuals to this type of habitat. Among perennial populations, there was a foreign advantage. Lower elevation perennial forms had greater fecundity of both seedlings and rosettes, and less investment in belowground rhizomes. These patterns persisted despite variation in weather between the two years, with a strong drought in 2013 and a lesser one in 2014. This foreign advantage could be influenced by local inbreeding in the focal site, climate change shifting the geographic range of the climate match, variation in ecological history of populations, or a combination of factors.

The Mimulus system pursued by Peterson et al. is especially interesting because of the diversity of species within the clade (Beardsley et al., 2004; Barker et al., 2012) and the ongoing research in the taxonomic (e.g. Nesom, 2012) and systematic relationships. Systems with gradients of variation in traits and ecological diversity of habitat types as in Mimulus provide opportunities to investigate the complexity of environment population interactions, while allowing for an evaluation of continuous variation in life history within a single clade. Studies in systems with hierarchies of form can provide models for investigation of specific traits associated with potential for range shifts (Wu et al., 2008) and species boundaries.

With two years of sampling and detailed measurements of fitness contributions throughout the lifespan, Peterson et al. effectively used a common-garden study to dissect hierarchical levels of local adaptation and foreign advantage in Mimulus. Although in many ways a model of a well-designed experiment, this does not minimize the need for reciprocal-transplant experiments. For particular focal comparisons, reciprocal-transplant experiments will remain the gold standard for showing trade-offs in performance among sites and through time. More importantly, reciprocal-transplant experiments are far more powerful for specifically examining plasticity of traits. In certain circumstances, the plasticity of traits is the primary mechanism by which an organism adapts to local environmental conditions. It has been seen in Mimulus that trichome density (Holeski, 2007; Colicchio et al., 2015) and the amount and timing of seed germination (Vickery, 1983) are plastic traits; with each trait responding differently to distinct ecological settings. Reciprocal-transplant experiments allow for the ability and range of such plastic traits to be more easily tested in true multivariate environmental conditions. Similarly, lifespan, one of the major life-history traits that vary across the Mimulus complex, could still be tested in multiple sites over multiple years to examine environmental conditions in which annual or perennial behavior is favored.

Common-garden studies such as this can help target the most informative comparisons of populations and focal traits. Similarly, studies like this one demonstrate the need to pair sequencing studies, which may look for outliers or other signatures of selection based on patterns of molecular variation alone (Savolainen et al., 2013), with detailed common-garden studies (e.g. de Villemereuil et al., 2016).
Carefully designed and executed common-garden studies, such as the one performed by Peterson et al. can illuminate the key patterns of differentiation among populations, showing which particular life stages or developmental allocations differ most among them. Addressing these challenges will benefit from joint investigations of systematists, molecular geneticists, and evolutionary ecologists, and may shed new light on old questions in agriculture and forestry.

\section{Acknowledgements}

The authors thank the New Phytologist staff and Editor for the opportunity to champion this work. E.J.B.v.W. is supported by NSF-PGRP 1339346 and USAID AID-OAA-A-14-00008. C.J.M. is supported by NSF-IOS 1146977, NSF-OCE 1357386 and NSF-IOS 1355106.

\section{Eric J. B. von Wettberg ${ }^{1}$, Edward Marques ${ }^{1}$ and Courtney J. Murren ${ }^{2}$}

${ }^{1}$ Department of Biological Sciences and International Center for Tropical Botany, Florida International University, Miami, FL 33199, USA;

${ }^{2}$ Department of Biology, College of Charleston, Charleston, SC 29424, USA

(*Author for correspondence: tel +1 305348 2298; email eric.vonwettberg@fiu.edu)

\section{References}

Barker WR, Nesom GL, Beardsley PM, Fraga NS. 2012. A taxonomic conspectus of Phrymaceae: a narrowed circumscriptions for Mimulus, new and resurrected genera, and new names and combinations. Phytoneuron 39: 1-60.

Beardsley PM, Schoenig SE, Whittall JB, Olmstead RG. 2004. Patterns of evolution in Western North American Mimulus (Phrymaceae). American Journal of Botany 91: 474-489.

Blanquart F, Kaltz O, Nuismer SL, Gandon S. 2013. A practical guide to measuring local adaptation. Ecology Letters 16: 1195-1205.

Caswell H. 2001. Matrix population models: construction, analysis, and interpretation. Sunderland, MA, USA: Sinauer Associates.

Colicchio JM, Monnahan PJ, Kelly JK, Hileman LC. 2015. Gene expression plasticity resulting from parental leaf damage in Mimulus guttatus. New Phytologist 205: 894-906.

Hall MC, Willis JH. 2006. Divergent selection on flowering time contributes to local adaptation in Mimulus guttatus populations. Evolution 60: 24662477.

Heisey WM, Clausen J, Keck DD. 1942. Relations between climate and intraspecific variation in plants. The American Naturalist 76: 5-22.

Hereford J. 2009. A quantitative survey of local adaptation and fitness trade-offs. The American Naturalist 173: 579-588.

Hoeksema J, Forde S. 2008. A meta-analysis of factors affecting local adaptation between interacting species. The American Naturalist 171: 275-290.

Holeski LM. 2007. Within and between generation phenotypic plasticity in trichome density of Mimulus guattatus. Journal of Evolutionary Biology 20: 2092-2100.

Ivey CT, Carr DE, Eubanks MD. 2004. Effects of inbreeding in Mimulus guttatus on tolerance to herbivory in natural environments. Ecology 85: 567-574.

Kawecki TJ, Ebert D. 2004. Conceptual issues in local adaptation. Ecology Letters 7: 1225-1241.

Lowry DB, Cotton Rockwood R, Willis JH. 2008. Ecological reproductive isolation of coast and inland races of Mimulus guttatus. Evolution 62: 21962214 . 
Nesom GL. 2012. Taxonomy of Erythranthe sect. Mimulosma (Phrymaceae). Phytoneuron 41: 1-36.

Núñez-Farfán J, Schlichting CD. 2001. Evolution in changing environments: the "synthetic" work of Clausen, Keck, and Hiesey. The Quarterly Review of Biology 76: 433-457.

Oduor AM, Leimu R, van Kleunen M. 2016. Invasive plant species are locally adapted just as frequently and at least as strongly as native plant species. Journal of Ecology. doi: 10.1111/1365-2745.12578.

Peterson ML, Kay KM, Angert AL. 2016. The scale of local adaptation in Mimulus guttatus: comparing life history races, ecotypes, and populations. New Phytologist 211: 345-356.

Savolainen O, Lascoux M, Merila J. 2013. Ecological genomics of local adaptation. Nature Reviews Genetics 14: 807-820.
Turesson G. 1922. The species and variety as ecological units. Hereditas 3: $100-113$

Vickery RK Jr. 1983. Plasticity and polymorphism in seed germination of Mimulus guttatus. Western North American Naturalist 43: 470-474.

de Villemereuil P, Gaggiotti OE, Mouterde M, Till-Bottraud I. 2016. Common garden experiments in the genomic era: new perspectives and opportunities. Heredity 116: 249-254.

Wu CA, Lowry DB, Cooley AM, Wright KM, Lee YW, Willis JH. 2008. Mimulus is an emerging model system for the integration of ecological and genomic studies. Heredity 100: 220-230.

Key words: common-garden experiment, foreign advantage, life-table response experiment, local adaptation, Mimulus guttatus, reciprocal-transplant experiment.

\section{About New Phytologist}

- New Phytologist is an electronic (online-only) journal owned by the New Phytologist Trust, a not-for-profit organization dedicated to the promotion of plant science, facilitating projects from symposia to free access for our Tansley reviews.

- Regular papers, Letters, Research reviews, Rapid reports and both Modelling/Theory and Methods papers are encouraged. We are committed to rapid processing, from online submission through to publication 'as ready' via Early View - our average time to decision is $<27$ days. There are no page or colour charges and a PDF version will be provided for each article.

- The journal is available online at Wiley Online Library. Visit www.newphytologist.com to search the articles and register for table of contents email alerts.

- If you have any questions, do get in touch with Central Office (np-centraloffice@lancaster.ac.uk) or, if it is more convenient, our USA Office (np-usaoffice@lancaster.ac.uk)

- For submission instructions, subscription and all the latest information visit www.newphytologist.com 